Teaching Point

Nephrology Dialysis Transplantation

(Section Editor: K. Kühn)

\title{
The lady with nephrotic-range proteinuria and necroses after exposure to cold
}

\author{
J. A. Schifferli \\ Kantonsspital Basel, Departement Innere Medizin, Petersgraben 4, CH-4031 Basel, Switzerland
}

A 55-year-old Italian patient had known proteinuria and hypertension. She complained of burning sensations in her legs which she thought improved during exposure to cold. Consequently, during the night she applied ice cubes to her leg. The photograph taken $12 \mathrm{~h}$ later showed the effect of in-vivo cryoprecipitation with severe necrotic lesions (Figure 1A). Serum from this patient contained a mixed cryoglobulin (Figure 1B), i.e. monoclonal IgM rheumatoid factor/ polyclonal IgG.

In addition to nephrotic-range proteinuria and hypertension the patient had a history of polyarthralgia. The clinical suspicion of membranoproliferative glomerulonephritis (MPGN) was confirmed by renal biopsy, which revealed deposits of $\mathrm{IgG}, \mathrm{IgM}, \mathrm{Clq}, \mathrm{C} 4$ and $C 3$. The serology was positive for hepatitis $C$ virus (HCV) and the serum contained HCV-RNA. Although the liver function tests were normal the biopsy demonstrated prominent infiltration of portal spaces with small round lymphocytes (Figure IC). Similar infiltrations of lymphoid nodules can be found in the bone marrow (Figure 1D), the salivary glands (identical to that found in Sjögren's syndrome [1]), the kidney, etc.

In the past few years serological tests and RNA amplification techniques have indicated that most patients with so-called mixed essential cryoglobulinaemia are infected with $\mathrm{HCV}$. A prospective study demonstrated that most of these patients have indeed chronic liver disease despite normal or only slightly abnormal liver function tests $[2,3]$.

In patients without advanced cirrhosis, the response to interferon- $\alpha$ is good in at least $50 \%$ of patients. This should be considered as initial therapy before immunosuppressive drugs are tried [4]. The patients must be monitored closely because of possible side-effects of interferon- $\alpha$. The patient illustrated here was dramatically improved by interferon- $\alpha$. Nephrotic syndrome and hypertension disappeared, although some cryoglobulins persisted.

Recently, many patients with MPGN but without cryoglobulin were also shown to be infected with HCV [5]. There is no report to indicate that such patients improve on interferon- $\alpha$ therapy'.

\section{References}

1. Haddad J, Deny P, Munz-Gotheil C et al. Lymphocytic sialadenitis of Sjögren's syndrome associated with chronic hepatitis $\mathrm{C}$ virus liver disease. Lancet 1992; 339: 321-323

2. Pascual M, Perrin L, Giostra E, Schifferli JA. Hepatitis C virus in patients with cryoglobulinemia type II. J Infect Dis 1990; 162: $569-570$

3. Pechère-Bertschi A, Perrin L, de Saussure $P$, Widmann JJ, Giostra E, Schifferli JA. Hepatitis C: a possible aetiology for cryoglobulinaemia type II. Clin Exp Immunol 1992; 89: 419-422

4. Misiani R, Bellavita P, Fenili D. Interferon alpha 2a therapy in cryoglobulinemia associated with hepatitis C virus. $N$ Engl $J$ Med 1994; 330: 751-756

5. Johnson RJ, Gretch DR, Yamabe $\mathrm{H}$ et al. Membranoproliferative glomerulonephritis associated with hepatitis C virus infection. $N$ Engl $J$ Med 1993; 328: 465-470 

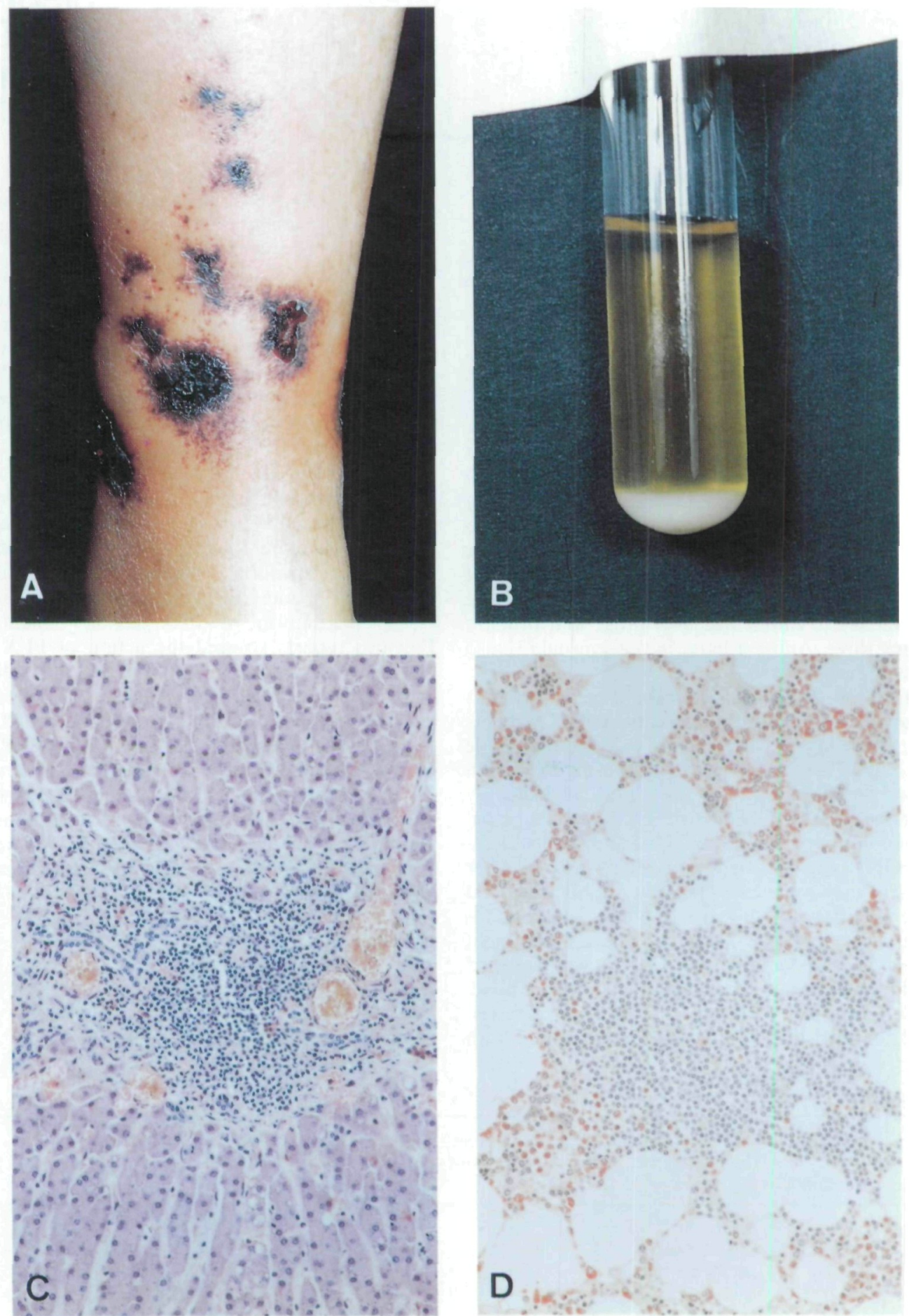

Fig. 1. 